\title{
Evaluating the Implication of Open Badges in an Open Learning Environment to Higher Education
}

\author{
Xiaoxing Ma \\ Department of Computer Science and Technology, \\ Tianjin University of Finance \& Economics, \\ Tianjin \\ xxingl@163.com
}

\begin{abstract}
MOOC failed to disrupt higher education, because MOOC only able to provide unmatched price only to expose you to a world-class professors, they do not provide a formal university degree. Now open badge which is electronic certification can indicate the learner has the specific skills and knowledge, and network links will prove how they get this badge for any organization, university or other institution can be issued to. This paper outlines Open Badge concept, describes the design, development, and implementation of Open Badges, highlights the observations and challenges that emerged for higher education institution.
\end{abstract}

Keywords-component; open badge; MOOC; higher education; online learning.

\section{INTRODUCTION}

Three years ago, technology has begun to change higher education. So what is really changing?

The development of open educational resources began from MIT OCW as early as 2002; MIT put their lots of courses on the Internet for people to learn for free. Later, with the OER, a growing number of universities and educational institutions will share high-quality resources[6]. A few months in early 2012, the top scientists from Harvard University, Stanford University and the Massachusetts Institute of Technology founded three companies, providing MOOC for anyone in the world through the Internet. The course are completely free, millions of student have enroll. Authorities said it was a revolution for higher education. Free, high-quality content as a selling point to MOOC, providing extensive online support for learners, including arrange course tasks, assessment of learning effect, interact between students and teachers, and even provide a certificate for students successful complete of the course learning[3].

Coursera, a for-profit MOOC platform, offers a range of courses and professional similar to college courses. The model of Coursera and university cooperation reached a consensus, based on Coursera technology, provides the development and support for the university teachers, or the team to develop and design of network course learning, work together to provide services and support for students from all over the world. Currently, Coursera has been developed to 313 courses, 2.8 million students are enrolled. Its course organization is mainly in the form of video lectures, online testing, and online and offline discussions, fully reflects the needs of studentcentered learning design[4].

Today, however, the momentum of the traditional higher education admissions remained strong; college students pay higher tuition than ever before, but also more affordable loans. University did not seem ready to join the ranks of video stores, and they got to like the ashes of history - at least not yet.

\section{TRADITIONAL Higher EDUCATION}

MOOC failed to disrupt higher education, which has nothing to do with the quality of the course itself, where many courses are quite good and is getting better and better. And compared to this technological revolution, the University still take an advantage, because MOOC only able to provide unmatched price only to expose you to a world-class professors, they do not provide a formal university degree, and this degree often allow you to find a job. Facts have proved the degree is the biggest reason college students make great efforts and pay expensive tuition.

The traditional university degree passed out several messages. Top universities tend to pick the best and brightest students through the admissions exam. This in itself is valuable information. That is why the "Harvard dropout" and "Harvard Graduate" to convey information to the job market are almost identical: "This man could have been good enough to enter Harvard University." College degree gives meaning to the courses and structure. Bachelor's degree means more than college credits. In order to graduate, students need to get a certain number of senior and junior course credits, complete major professional courses, as well as a few courses in natural and humanistic science. Now graduated from college is a necessary condition to obtain a bachelor's degree, but the past is not the case[7].

The most important is that the traditional university degree deeply integrated into the system of government regulation and standardization of human resource practices. If you do not have a bachelor's degree, no matter how good teacher you are, the public schools won't hire you. Private employers often choose a college degree as a cheap and fast way of picking talent, in order to determine whether the candidates have some basic qualities, mainly self-discipline and the ability to obtain college credits are required. Free online courses do not completely change the education system, unless there are free or charging 
low can issue certificates system, similar to the traditional colleges, this system is not controlled by the traditional colleges and universities, and the certificate can bring employment opportunities. Now technology innovators are working to achieve this. Present, information technology is expected to change the way to get a college degree. When that happens, the economic foundation of universities will really begin to shake.

\section{MOOC}

Tutors who want to commence a MOOC course on Coursera, you must submit application to relevant agencies first. Subsequent, agencies take examinations on professionalism, teaching ability and other aspects of tutors, Tutors who meet the relevant requirements are allowed to commence courses on Coursera, this strict auditing system ensure the quality of MOOC courses.

Tutors recorded videos about sessions for MOOC courses first, release announcement and curriculum programs, and so publish curriculum resources regularly, arrange chapter and midterm, final exam. Learners can have an overview of the curriculum by read course descriptions, browse course evaluation, and then register for classes and complete the corresponding course of study. Coursera platform also establish discussion group, and organize offline meeting timely. It is worth mentioning that the only those who submit the assignment on time, and pass the exam will be awarded course completion proof.

Functional design of Coursera platform can effectively assist tutors to commence a series of educational activities. Upon beginning the course, tutors will regularly publish course information, curriculum model for analysis, Coursera lectures is very similar with the traditional teaching model, designed to enable students to master the content of classroom teaching, Characterized by teaching rule: exercises and quizzes., including the provision of video lectures, chapter quizzes and course examinations. Coursera close to the interior design of university curriculum model, reduces the difficulty of MOOC integration with universities, enhance the feasibility of conduct MOOC based blended learning in universities.

Evaluation of the learning process has been a chronic problem in e-learning. Large-scale online course made stunning innovation on monitoring and evaluation of the student learning process. Coursera innovative use the approach that machine evaluations for objective questions for timely feedback, use approach that peer assessment during students to solve the subjective problem for evaluation, this initiative was relevant by other online course platform. After learner complete to learn a MOOC courses and pass examination, learner can get an electronic certificate, as a recognition and affirmation for learner to participate in online learning. However, Coursera and Udacity dedicated to providing quality education platform for students around the world, will be faced the problem how to make students efforts on the platform recognized by society in present. Coursera and Udacity are trying to cooperate with universities; learners learn courses on the platform can be converted to the same courses credit.
Five courses credits of Coursera have been obtained official recognition ACT CREDIT. Udacity cooperate with San Jose State University to providing credit certification in five courses, and these credits can be converse within the system of St. Jose State University. Each course will cost $\$ 150$, the course is limited to low-grade classes and remedial classes, and the number of students is limited to only 300 people, half the number of university courses in general. But in China, there still no courses credits recognition by universities. This is a very important step in inspection of long-term development potential for MOOC, but also can test whether this new model is to mobilize students around the world to complete their studies, participate in learning. This large-scale online course, it will be a milestone leap during combination of mainstream higher education[8].

Developed the Firefox browser organization Mozilla Foundation spent a few years launched a so-called Open Badges project. This badge is an electronic certification for any organization, university or other institution can be issued to indicate the learner has the specific skills and knowledge, and network links will prove how they get this badge[1].

In the early days of digital badge applications, various organizations have developed and applied in their own badge system. These practices expose many problems within badge development for the complexity of the Internet community: wide range of uncertainty of the badge, adopted different standards and so on. These reduce the credibility and availability of the digital badge, makes promotion and application difficult. To solve these problems, providing standardized digital badge creation, publishing and authentication technology architecture, open-source software organizations Mozilla Foundation, launched the Open Badge projects. In order to meet the learning needs of ubiquitous technology, the system must support different badge publishing sources, different display platform. This is similar to the currency circulation system. The fully reflect the function of digital badge, you need a badge technology support at different sites and can mix and match different objects Thus, standardized, consistent data description format and standardized processes, process of being born, emerging in contrast, is used to unify the different users in the badge production, publishing, access, collect and display related work.

\section{Technology of Open Badges}

Open Badges allows any learner with a unique identity collected badges from different sites, and then in the different sites in a simple way to show to other people. From the perspective of the norms and standards, such standards must be open and decentralized, must integrate organic whole ecosystem of technologies and practices, put the right to choose to end users, then the standards will have vitality. Open Badge $\mathrm{s}$ is an online version of the entity insignia, some identity, some property or some kind of achievement can be identified through badges. The digital badge after produced can have the status that unverified and verified.

In OBI framework, digital badge is a PNG format image file, embedded with some digital watermark in JSON format. OBI is a technology platform that is the based technical framework of Internet publishing and sharing badge. The 
technical framework supports independent badge issuers and exhibitor, provides a reference implementation for badge backpack, including metadata specifications, APIs, frameworks and certification infrastructure and other modules.

In the OBI model are the main winners, publisher, exhibitor three characters, These three roles are not necessarily people, it can be a computer; these three are not necessarily independent[9].

\section{A. Earner}

Earner is the people who get badge. They devote their energies to complete a task on behalf of acquire the badge. In the badge system, it is need for clear evidence to obtain a badge to prove its achievements; these achievements can be knowledge, skills or abilities.

\section{B. Issuer}

Issuer creates a badge, definite what skills and knowledge badge represents, and someone possess the proof and programs of the badge stipulate and skills knowledge.

\section{Displayer}

Displayer provides the ability to display a badge, both individual blog sites like WordPres, including social networks like Facebook, there may resume search site like LinkedIn. The user's badge retrieves from badge backpack, displayed in all kinds of websites.

In addition, there are other more common role such as signer and endorser, which is an individual, organization or institution to verify authenticity of badge.

\section{OBI Technology Framwork}

Entire technology framework consist of badge backpack, metadata specification, API, authentication channels and endorsement, validation channels and other parts, electronic badge production is the core of the whole communicate, produced by the issuer. Badge production is the first step of the whole process.

In order to make a badge for easy carrying and fault tolerant, OBI framework provides a set of production specifications, including the qualifications of the badge issuer, metadata specification and badges repression.

Before the production, badge issuer must have some prerequisites:

1) Server First, issuer must have a server link to the Internet, which should can send Post requests and read JSON responses. The server is not only the necessary part of the badge production, also prerequisite for the badge issued; it is the key part of the certification badge.

2) Email address Second, issuer must record winner badge email address to send notifications when badges issued to them.

3) Repress Third, issuer must be able to online communicate with the repression service provided by Mozilla, complete repressing tasks, convenient badge circulation.
4) PNG format images Fourth, issuer must prepare PNG format images represent the meaning of a particular badge in advance.

\section{E. Metadata Specification}

Metadata specification is the core of badge production. Metadata contains all information required like knowledge and verify for a badge, the copy of the data is embedded in PNG format picture repression in JSON format, the noumenon of the metadata stored permanently in the issuer's server, used to verify badge in the validation session.

\section{F. Repression}

Repression is the key that make sure badge will smoothly circulation within OBI. In OBI, badge repression needs to be done before issuing work, generate portable electronic badge files. Under normal circumstances, the badge repression is completed by the Issuer API. But if people want to get the badge outside OBI storage, badge issuers complete repression work with Mozilla Baking Service when issuing badges.

\section{Measure of Open BaDges}

Traditional institutions are trying to issue this badge, including Michigan State University and the University of Illinois at Urbana-Champaign. Some organizations also joining, such as the National Oceanic and Atmospheric Administration, Smithsonian Institution, and the YMCA of Greater New York. Most importantly, the recognition of the scope of this badge is not limited to people in the university learned, and it will not be the exclusive control by the university. Whether at work, at home, people can learn all life. Currently universities are monopoly in degree that can bring a job, the fact that aptly explains why they can have increased tuition every year.

MOOC provider is also moving in this direction. They have been providing similar certificates. Coursera launched a socalled capstone project; students can demonstrate the skills gained and obtain certification through this project, a total cost of $\$ 470[6]$.

Coursera provide a course named Data Science sequence, this course are taught by professor from Johns Hopkins University, including nine four-week courses, such as exploratory data analysis, regression models and machine learning. Capstone project requires the students to develop a data model and visual forms of communicate the results of the analysis. The certificate has been officially recognized by Coursera and Johns Hopkins.

EDX has the similar project. EDX is a MOOC nonprofit organization ran by Harvard University and the Massachusetts Institute of Technology.

Inevitably, this new certificate in order to obtain widely recognized by employers and government regulators, and the time will inevitably lag. The human resources department knows the details of a bachelor's degree, while the digital certification is the new things. But employers have a strong motivation in this direction: the traditional university degree does not adequately expressed candidates abilities.

College transcripts like a nightmare, contains various disciplines rating scale, the cryptic course ID, and a steady 
decline in the value of the score. However, transcripts will strengthen the class prejudice in university admissions system the total number of outstanding candidates of a large-scale and relatively open traditional public university, with the same number of a smaller and private specificity universities. Assuming each university's candidates are 500 people. But the 200 people of the public university may graduate together and more than 3000 other students and this 200 private university may only graduates with 300 people together. The diplomas and transcripts provide little useful information for employers to separate excellent and the rest of these people, so they let the private university graduates take an advantage[8].

New digital certificates can solve this problem by providing more multiply exponentially information. Think about what you do all the day at the university. Unless you are a fresh graduate, how many you can remember and now can think of it in some way? The skills you acquired in a different position? However, the digital learning environment can save almost all of this and make it systematic. Learner still have all my learning material includes class notes, tests, assignments, syllabus and scores, click on the EDX folder. In contrast, the "real" university courses are lost in history, and only on a paper transcript is an incredible score, indicating that they had really happened.

\section{CONCLUSION}

Open the certificate system allows people to control their own relevant information, including knowledge learned in college and skills learned in other places, all this information can be presented directly in front of the employer. More and more in people through a network of long-distance exchange today, control is essential to prove that you have online education experience[10]. More and more in people doing long-distance communicate through network today, control the online education experience is essential.

It also brought new challenges for all of these employers have to filtering additional information. Although selecting a college degree as the criteria cause a lot of problems, but this way can quickly and easily digest the information. But, the computer is good at process large amounts of information. Scientists from Carnegie Mellon University are designing "can be machine readable" open badge, which means that by the search algorithm, employers can find these badges, and in order to locate people with specific skills.

Protection of private and personal information is an important part of the development of the digital age. However, people also want certain kinds of information open as possible, for example, when they are very good at a specific job, and want to find a employers who has such recruitment needs. A company such as LinkedIn is creating a new tool that allows people to describe their ability to be able to do the job. In contrast, the university degrees contain too few information, and will never change.

In the long term, MOOCs is likely to be a key step in promoting the reform of higher education. However, when all types of students and learners have the opportunity to obtain a digital certificate that is created for the modern world; people will feel their true impact. Then, these people will be able to acquire skills, and now it takes only a fraction of the cost of college, you can get the opportunity for jobs.

\section{ACKNOWLEDGMENT}

Open Course Ware ((i.e. OCW).

Open Educational Resources Development (i.e. OER).

Massive Open Online Courses (i.e. MOOC).

American Council on Education (i.e. ACT CREDIT).

Open Badge Infrastructure (i.e. OBI).

Application Programming Interface (i.e. API).

Identity (i.e. ID).

Java Script Object Notation (i.e. JSON).

\section{REFERENCES}

[1] Jelena Jovanovic, Vladan Devedzic, “Open Badges: Challenges and Opportunities,” Advances in Web-Based Learning - ICWL 2014 Lecture Notes in Computer Science, vol. 8613, pp. 56-65, August 2014.

[2] Myllymäki M, Hakala I,” Open Badges in Higher Education," EDULEARN14 Proceedings. 6th International Conference on Education and New Learning Technologies, IATED Academy, pp. 2027-2034,Jan 2015.

[3] Randall, Daniel L, "Giving Credit Where Credit Is Due: Designing Open Badges for a Technology Integration Course,” Linking Research and Practice to Improve Learning, vol. 57, Springer, Nov 2013-, pp. 88-95.

[4] Ian Glover, "Open Badges: A Visual Method of Recognizing Achievement and Increasing Learner Motivation,” Student Engagement and Experiment Jornal, vol.2, 2013.

[5] Li Qing,” Technique Review on Mozilla Open Badges Specification,” Modern Distance Education Research, Jan 2014.

[6] Khe Foon Hew," Student perceptions of peer versus instructor facilitation of asynchronous online discussions: further findings from three cases,” Springer, Sep 2014.

[7] Steffi Engert, Sandrina Heinrich, "EUNIS 2013: E-Learning Challenges of the Next Phase,” 2013.

[8] J. Albert Laso, P. Pernías Peco, "Using Open Badges as certification in a MOOC," 6th International Conference of Education, Research and Innovation ICERI2013 Proceedings, pp. 1809-1818, 2013.

[9] MG Moore, "Independent Learning, MOOCs, and the Open Badges Infrastructure,” American Journal of Distance Education,vol.27, pp. 7576, 2013.

[10] S Cross, D Whitelock, "The use, role and reception of open badges as a method for formative and summative reward in two Massive Open Online Courses,” International Journal of e-Assessment,vol.1, 2014. 